\title{
TRAJETÓRIAS DA CONSTRUÇÃO DA IDENTIDADE DE PROFESSORAS DO ENSINO BÁSICO COMO EDUCADORAS AMBIENTAIS
}

\author{
Ariane Di Tullio ${ }^{1}$ \\ Haydée Torres de Oliveira ${ }^{2}$
}

\begin{abstract}
Resumo
Diante da expansão da educação ambiental (EA) no ensino formal, buscamos compreender as trajetórias por meio das quais professoras no ensino básico se aproximaram desse campo, bem como os processos de construção das suas identidades como educadoras ambientais. Utilizamos como referencial teórico a hermenêutica filosófica de Hans-Georg Gadamer e a pedagogia dialógica de Paulo Freire, sendo que as narrativas das entrevistadas foram analisadas à luz da análise textual discursiva. Percebemos que as professoras têm se aproximado da EA por diferentes vias, que se inter-relacionam de maneira complexa. A inserção da dimensão ambiental nas práticas pedagógicas e a busca de formação contribuem para a construção de suas identidades como educadoras ambientais, mesmo que heterogêneas e provisórias, sujeitas às oportunidades de atuação. As práticas também possibilitam sua identificação com os valores do ideário ambientalista em âmbitos profissional e pessoal.
\end{abstract}

Palavras-chave: Trajetórias. Identidade. Hermenêutica filosófica.

\section{PATHWAYS OF IDENTITY CONSTRUCTION OF BASIC SCHOOL TEACHERS AS ENVIRONMENTAL EDUCATORS}

\begin{abstract}
Given the expansion of environmental education (EE) in formal education, we seek to understand the pathways by which primary school teachers approach it, as well as the processes of construction of their identities as environmental educators. We based our study in Hans-Georg Gadamer's philosophical hermeneutics and Paulo Freire's dialogical pedagogy. The narratives of the interviewed teachers were analyzed using discursive textual analysis. We found that the teachers have approached EE by different pathways that interrelate in complex ways. The integration of the environmental dimension in teaching practices and / or seeking education through coursework contribute to the construction of their identities as environmental educators, notwithstanding heterogeneous and provisional, depending on opportunities for action. The practices also enable their identification with the values of the environmentalist ideology in professional and personal spheres.
\end{abstract}

Keywords: Pathways. Identity. Philosophic hermeneutics.

\footnotetext{
${ }^{1}$ Doutoranda do Programa de Pós-Graduação em Ecologia e Recursos Naturais (UFSCar). Bolsista CNPq. Membro do GEPEA/UFSCar.

${ }^{2}$ Profa. Associada IV - Laboratório de Educação Ambiental - LEA / Depto. de Ciências Ambientais (DCAm/UFSCar). Líder do GEPEA/UFSCar.
} 


\title{
TRAYECTORIAS DE LA CONSTRUCCIÓN DE LA IDENTIDAD DE MAESTRAS DE LA EDUCACIÓN BÁSICA COMO EDUCADORAS AMBIENTALES
}

\begin{abstract}
Resumen
Debido a la expansión de la educación ambiental (EA) en la educación formal, buscamos entender las vías por las que los maestros de educación básica llegaron a este campo, así como los procesos de construcción de su identidad como educadores ambientales. Utilizamos el marco teórico de la hermenéutica filosófica de Hans-Georg Gadamer y la pedagogía dialógica de Paulo Freire, y los relatos de los entrevistados fueron analizados a la luz del análisis textual discursiva. Nos damos cuenta de que los maestros se han acercado a EA por diferentes rutas, que están relacionadas entre sí de manera compleja. La inserción de la dimensión ambiental en las prácticas de enseñanza y la búsqueda de la formación contribuyen a la construcción de sus identidades como educadores ambientales, aunque heterogénea y provisional, sujeta a las posibilidades de actuación. Las prácticas también permiten su identificación con los valores de las ideas ambientales en los niveles profesionales y personales.
\end{abstract}

Palabras-clave: Trayectorias. Identidad. Hermenéutica filosófica.

\section{Introdução}

Durante os anos de 2011 e 2012, a Prefeitura Municipal de São Carlos por meio da Secretaria Municipal de Educação e da Coordenadoria de Meio Ambiente desenvolveu o projeto ProMEA na Rede. Seu objetivo principal ${ }^{3}$ era institucionalizar a EA enquanto política pública na rede municipal de ensino, visando o efetivo enraizamento das ações, projetos e programas educativos socioambientais na sociedade sancarlense. O ProMEA na Rede teve seus fundamentos nos princípios e diretrizes do Programa Municipal de Educação Ambiental de São Carlos - o ProMEA-SC ${ }^{4}$ - (SÃO CARLOS, 2008) que foi concebido com base na Política Municipal de Educação Ambiental - Lei 14.795/2008) - (SÃO CARLOS, 2008a), sendo que os dois estão de acordo com a Política Nacional de Educação Ambiental - Lei 9.795/1999 - (BRASIL, 1999) e com o Programa Nacional de Educação Ambiental ProNEA (BRASIL, 2005).

Foram selecionadas professoras concursadas, que dedicaram $10 \mathrm{~h}$ semanais da sua jornada de trabalho para atuação como articuladoras da EA entre as escolas e a comunidade, as Educadoras Ambientais Locais (EALs). Em 2011, seis professoras participaram do projeto e, em 2012, esse número foi ampliado para dez. Duas das EALs originais não participaram da segunda fase, e uma nova professora foi selecionada para atuar como coordenadora do grupo. Assim sendo, o ProMEA na Rede se constituiu como um grupo de trabalho, formado por professoras do ensino básico, gestoras educacionais e uma das autoras deste trabalho no desenvolvimento da sua pesquisa de doutorado junto à UFSCar. O foco do grupo estava no desenvolvimento e na implementação de ações e práticas de EA, envolvendo as unidades escolares e comunidades de entorno.

Considerando que cada professora participante atuou como educadora ambiental durante pelo menos um ano letivo, buscamos compreender suas motivações e trajetórias de aproximação com a EA, bem como os caminhos da construção das suas identidades enquanto educadoras ambientais. Diante do exposto, as questões que buscamos responder com essa pesquisa foram: por meio de quais caminhos, professoras da educação básica se aproximam da EA? As professoras que optam por trabalhar com EA se identificam com o ideário

\footnotetext{
${ }^{3}$ Minuta do Projeto ProMEA na Rede, fornecida pela Coordenadoria de Meio Ambiente.

${ }^{4}$ Aprovado em 2008 pela Resolução n ${ }^{\circ}$ 001/08 do COMDEMA-SC.
} 
ambiental? E, por fim, quais os caminhos pelos quais elas constroem sua identidade enquanto educadoras ambientais? Sendo assim, os objetivos do presente artigo consistem em compreender as trajetórias pelas quais professoras do ensino básico se aproximaram da EA, bem como o processo de construção das suas identidades como educadoras ambientais.

\section{Possibilidades da hermenêutica filosófica no estudo das identidades}

A formação da identidade é uma questão complexa, controversa e que envolve diversas nuances (PAYNE, 2000). Hall (2000) define identidade como uma convergência total ou parcial entre o sujeito e as posições construídas pelas práticas discursivas, sendo que ela também pode ser construída na diferença, em contraposição àquilo que não é, àquilo que falta no outro. Ainda segundo o mesmo autor, a identidade não é algo estável e idêntico ao longo do tempo, estando em processo de construção constante e podendo ser sustentada ou abandonada a qualquer momento. Dubar (2006) também define identidade como o resultado de uma identificação contingente, relacionada à singularidade de uma pessoa em relação à outra, mas também aos pontos comuns entre elas, sendo que não há identidade sem alteridade.

Portanto, a construção de identidades individuais e coletivas envolve processos dinâmicos, socialmente construídos e constantemente mediados pela participação das pessoas nas práticas, possibilitando que elas compartilhem objetivos, recursos e conhecimentos, aprendendo umas com as outras e construindo valores e repertórios comuns (SPADARO et al., 2012). Embora a identidade seja construída na relação com o outro, não se pode desprezar o papel do sujeito, de maneira que ela é formada na mediação entre escolhas pessoais e influências externas (DILLON; KELSEY; ARISTIZABAL, 1999).

A sensação de pertencimento a um grupo consiste na percepção da similaridade aos outros membros desse grupo e o reconhecimento de uma interdependência entre eles, de maneira que o sujeito se reconhece como parte do todo (SPADARO et al., 2012). As/Os educadoras/es ${ }^{5}$ ambientais possuem variados graus de identificação e adesão aos atributos e valores do sujeito ecológico, que consiste em um perfil ideal, uma utopia que serve de modelo de vida, orientado pelos princípios e valores do ideário ecológico (CARVALHO, 2003). Ainda segundo essa autora, a internalização desses princípios e valores contribui para o reconhecimento pelos pares e para a legitimação no campo ambiental. Payne (2000) argumenta que formar e manter essa identidade não é um processo definitivo, ao contrário, requer lutas constantes para superar as dificuldades.

Adotamos como referencial teórico desse trabalho a hermenêutica filosófica de HansGeorg Gadamer e a pedagogia dialógica de Paulo Freire, por meio das quais assumimos uma pesquisa com epistemologia intersubjetiva, na qual a construção do conhecimento acontece por meio do diálogo entre as pessoas sobre suas experiências (IARED; DI TULLIO; OLIVEIRA, 2012). Acreditamos que tais referenciais podem contribuir para a compreensão dos processos identitários das/os educadoras/es ambientais, especificamente no que se refere às maneiras pelas quais suas identidades individuais e coletivas são construídas, sustentadas e/ou desconstruídas ao longo do tempo.

Entre as abordagens (auto)biográficas, normalmente utilizadas em pesquisas sobre trajetórias de vida e identidade, por permitirem o encontro entre a historicidade e o sujeito (CARVALHO, 2006), optamos pela pesquisa narrativa, que julgamos coerente com nosso referencial teórico, pois consiste em uma estratégia de compreensão do sentido da experiência vivida por meio da narração da mesma (MINAYO, 2010).

\footnotetext{
${ }^{5}$ Coerentemente com o referencial teórico utilizado, optamos pelo uso da linguagem não sexista ao longo do texto.
} 
A hermenêutica filosófica possibilita compreender os sentidos que as pessoas atribuem às suas experiências, por meio da linguagem, recriando tais experiências e trazendo-as do âmbito pré-compreensivo para o compreensivo (GADAMER, 2005). Assim sendo, por meio das narrativas, as pessoas passam a compreender suas experiências, pois, na perspectiva gadameriana, "é no dizer que o pensar se realiza" (HERMANN, 2002, p.68), ou seja, a linguagem está intimamente ligada ao pensamento. As lembranças registradas nas narrativas não se constituem em uma reprodução das experiências, ao contrário, são situações criativas, pois ao narrar suas vivências, as pessoas as interpretam, reinventando e reconstruindo seus sentidos, tal como se refletem nas experiências presentes (HART, 2002; CARVALHO, 2003; DIAS, 2007). Segundo Gadamer (2005), todo entendimento é interpretação, portanto ao narrar suas experiências, o sujeito torna-se intérprete de si mesmo, criando novos sentidos para os fatos vividos, sendo que, nesse processo ele se posiciona, (re)criando também sua identidade (CARVALHO, 2003). Ao tentar compreender as narrativas, a/o pesquisador/a também assume um papel interpretativo, dialogando com elas e tornando-se mais um/a interlocutor/a na produção do conhecimento (FREIRE, 1997; CARVALHO, 2003). Assim, a narrativa é, constantemente, influenciada pela interpretação de ambos: narrador/a e pesquisador/a (HART, 2002).

Outra contribuição da hermenêutica filosófica para o estudo dos processos identitários é a compreensão das relações entre indivíduo, sociedade e historicidade (CARVALHO, 2003). A compreensão hermenêutica parte da historicidade humana, ou seja, nossa historicidade é condição de nossa compreensão (HERMANN, 2002; LAWN, 2010). "Não é a história que nos pertence, mas somos nós que pertencemos a ela. Muito antes de nos compreendermos na reflexão sobre o passado, já nos compreendemos naturalmente na família, na sociedade e no Estado em que vivemos" (GADAMER, 2005, p. 367). Freire (1980, p. 81) também se refere à historicidade na "negação do homem abstrato, isolado, solto, desligado do mundo, assim também na negação do mundo como uma realidade ausente dos homens". Porém, considerar a historicidade humana na compreensão de mundo, não significa assumir uma postura fatalista da realidade, ao contrário, um dos fundamentos da pedagogia crítica freiriana se manifesta na história como possibilidade e não como determinação (FREIRE, 1980, 2000). "Não apenas temos história, mas fazemos a história, que igualmente nos faz e que nos torna, portanto históricos" (FREIRE, 2000, p. 40). Desse modo, a história nos condiciona, mas não nos aprisiona, tornando as transformações possíveis (LAWN, 2010).

A partir da sua historicidade, cada pessoa possui um horizonte que consiste no "âmbito de visão que abarca e encerra tudo o que pode ser visto a partir de um determinado ponto" (GADAMER, 2005, p. 399). A compreensão acontece por meio do diálogo, um processo de fusão de horizontes, que significa que o sujeito alarga seu horizonte para que possa integrar o outro, produzindo novos significados a partir do encontro entre dois mundos (LAWN, 2010; GADAMER, 2005; TESTA, 2004). A dialogicidade também é uma característica da pedagogia freiriana. "O educador já não é o que apenas educa, mas o que, enquanto educa, é educado em diálogo com o educando que ao ser educado também educa" (FREIRE, 1980, p. 78), de maneira que as transformações acontecem em ambos (CARVALHO; GRÜN; AVANZI, 2009). Para isso, é preciso ter disponibilidade em se expor e em escutar (FREIRE, 1994). O verdadeiro diálogo acontece no encontro entre pessoas dispostas a ouvirem-se mutuamente e expor suas opiniões à avaliação do outro. Portanto, a verdade aparece na arte de olhar juntos e produzir um novo conceito (GADAMER, 2005; HERMANN, 2002). Portanto, a partir da reflexão e do diálogo, o sujeito (re)cria sentidos para suas experiências, se (re)posicionando e (re)criando também sua identidade (CARVALHO, 2006).

\section{Procedimentos metodológicos}


As professoras participantes da pesquisa constituem-se subjetividades únicas, com diferentes períodos de atuação em EA, experiências singulares de aproximação com o campo e em estágios distintos da construção das suas identidades enquanto educadoras ambientais. Embora tais experiências sejam impossíveis de ser comparadas, elas são vividas no coletivo, sofrendo influência deste e influenciando-o, de maneira que a subjetividade é construída na relação com o mundo e com os outros (CARVALHO, 2003; DIAS, 2007; FREIRE, 1997). Assim, buscamos revelar experiências semelhantes de aproximação com a EA e de construção da identidade, ainda que vividas de forma distinta por cada uma delas, pois tais experiências também podem estar presentes nas experiências desse grupo profissional como um todo (CARVALHO, 2003; DIAS, 2007).

Os relatos das professoras foram obtidos por meio de entrevistas semiestruturadas que, devido ao seu caráter interativo, já se constituíram em um momento de diálogo entre entrevistadora e entrevistada (LUDKE; ANDRÉ, 1986). Tal técnica permitiu que as professoras discorressem livremente sobre os caminhos e as motivações por meio das quais elas começaram a trabalhar a EA na escola e, também, se elas se consideravam educadoras ambientais, bem como as justificativas para tanto.

O convite para participar da pesquisa foi feito a todas as EALs pessoalmente, durante a última reunião do grupo em 2012, e também por meio de mensagem eletrônica. As perguntas foram entregues a elas antecipadamente, com a finalidade de evitar uma possível ansiedade que poderia anteceder a entrevista. Nove pessoas foram entrevistadas: sete EALs, a coordenadora do grupo e a gestora dos projetos de EA junto à Secretaria Municipal de Educação - SME. Cada uma das professoras definiu o local e o momento para a realização da sua entrevista, sendo que elas também autorizaram a gravação dessa interação em meio digital. Após a transcrição, as entrevistas foram enviadas para as EALs com objetivo de possibilitar um momento reflexivo sobre suas falas, bem como a correção ou complementação das informações fornecidas. Os nomes apresentados são fictícios e foram escolhidos com a finalidade de preservar o anonimato das participantes.

Pelo fato de a hermenêutica filosófica consistir em uma postura diante dos dados e não em um conjunto de procedimentos de análise (GADAMER, 2005), foi necessário selecionar uma técnica que nos auxiliasse na compreensão dos dados obtidos. Optamos, então, por um tipo específico de Análise de Conteúdo (AC), a Análise Textual Discursiva (ATD), que julgamos ser coerente com o referencial teórico supracitado. A AC constitui-se em um conjunto versátil de técnicas para analisar comunicações faladas ou escritas (BARDIN, 2008). Já a ATD pode ser entendida como um processo de produzir novas compreensões sobre os fenômenos investigados. Moraes e Galiazzi (2011) situam a ATD em um continuum entre a AC e a Análise do Discurso (AD), aproximando-se mais da primeira em termos da valorização da descrição e da interpretação enquanto partes do processo compreensivo e à busca da construção e reconstrução de compreensões sociais a partir das manifestações discursivas dos sujeitos da pesquisa.

Na primeira etapa da ATD, o corpus do trabalho foi fragmentado em unidades de sentido, de acordo com os objetivos e as questões de pesquisa. Para cada uma dessas unidades de sentido, estabelecemos um código numérico que indica a linha na qual o trecho se inicia no arquivo da transcrição da entrevista, o que permite localizá-la nos documentos originais. Em seguida, foi feito o agrupamento das unidades com base em aspectos semelhantes. De acordo com o referencial teórico adotado, optamos pelo uso de categorias emergentes, possibilitando a identificação das subjetividades manifestadas pelas participantes por ocasião das entrevistas. Além disso, a convivência de dois anos de uma das pesquisadoras com o grupo também trouxe elementos para a interpretação, que foi baseada nos materiais do corpus, mas, também, nas vivências acumuladas ao longo do processo. Do diálogo entre todos esses elementos 
emergiram as novas compreensões que, não consistem em uma interpretação única, final. Ao contrário, podem e devem ser reelaboradas por outros intérpretes em momentos posteriores.

\section{Trajetórias de aproximação das professoras com a educação ambiental}

Quando questionadas a respeito das suas motivações e interesses para trabalhar com a EA na escola, as professoras entrevistadas citaram, principalmente, a via profissional, ou seja, cursos de especialização e/ou extensão na área ou oportunidades de vivenciar a EA na sua prática pedagógica, como exemplificado nas falas a seguir.

Quando me chamavam [para dar aula em escola de] em fazenda eu sempre fazia uma horta... Eu sempre ensinei eles a mexerem com horta. Quando eu trabalhava com adulto, então eu sempre incluía no meu currículo alguma coisa de educação ambiental, plantas medicinais. Então, eu sempre procurei estar passando alguma coisa para eles que era uma coisa que eu acreditava e que eu gostava, eu gosto muito (LIDIANE 22).

Eu fiz um curso há um tempo atrás na Federal [UFSCar] sobre o meio ambiente, foi neste curso que tive os primeiros contatos com o tema. Eu não tinha nenhuma formação e também não tinha nenhuma informação mais detalhada [...] O curso me proporcionou conhecer um pouquinho do que era educação ambiental e como que eu poderia estar desenvolvendo alguma coisa dentro da escola. Então, foi a partir desse curso que começou a surgir ideias e ações sobre o tema (CRISTINA 14).

Embora o caminho profissional tenha sido bastante citado, não podemos desprezar o papel das vivências pessoais nessas escolhas. A professora Lidiane, por exemplo, relatou que mesmo antes de integrar o ProMEA na Rede, ela já procurava inserir práticas de EA nas suas aulas. Cristina contou que seu primeiro contato com a EA aconteceu por meio de um curso de formação oferecido pela UFSCar. Este despertou ideias de como trabalhar com a dimensão ambiental na escola. Como professoras da educação infantil ou primeira fase do ensino fundamental, todas as entrevistadas possuem Licenciatura em Pedagogia. A aproximação com a EA aconteceu posteriormente à graduação, pois nesse nível de ensino, a EA ainda apresenta uma institucionalização incipiente (OLIVEIRA; FARIAS; PAVESI, 2008; SORRENTINO; FERRARO JÚNIOR, 2010; MORALES, 2012; LOPES; ZANCUL, 2012), como podemos perceber a partir da fala da professora Cecília: "como professora eu sei que a minha formação foi muito falha em muitas coisas. E em educação ambiental é uma delas porque mesmo que isso seja cobrado da gente pra fazer algumas vezes, eu não sabia como fazer determinadas coisas (CECÍLIA 30).

A cada dia aumenta o número de educadoras/es ambientais que ingressam no campo durante o curso de graduação, devido aos esforços de ambientalização curricular desse nível de ensino, especialmente na última década (SORRENTINO; FERRARO JÚNIOR, 2010). Somando-se a isso, mais recentemente, em 2012, o Conselho Nacional de Educação aprovou as Diretrizes Curriculares Nacionais em Educação Ambiental (BRASIL, 2012) que, ao reafirmarem os princípios e diretrizes da PNEA, constituem mais um avanço em termos da institucionalização da EA em todos os níveis de ensino, pois reiteram que a EA deve integrar os projetos institucionais e pedagógicos da educação básica e superior. Apesar desses avanços, os desafios para o cumprimento efetivo dessas diretrizes ainda são muitos, visto que este envolve a articulação das instâncias estaduais e municipais de governo (GUIMARÃES; ALVES, 2012).

Porém, as professoras em exercício há mais tempo percebem que tiveram uma formação deficitária em EA durante a graduação. De fato, a EA tem sido inserida ao ensino superior por meio de disciplinas específicas, muitas vezes optativas, ou atividades extracurriculares isoladas resultantes do esforço pessoal de docentes comprometidos. Pelo fato de não terem sua continuidade assegurada, tais estratégias são insuficientes para 
incorporar, efetivamente, a dimensão ambiental na formação das/os futuras/os profissionais, sendo que a participação de estudantes nesse tipo de atividade é facultada pelo seu interesse e disponibilidade, tornando-se, então, uma escolha pessoal para além do currículo oferecido pela universidade (CASSINI, 2010; LOPES; ZANCUL, 2012). Além disso, no senso comum ainda prevalece uma EA tecnicista, mais voltada à gestão ambiental do que à formação de pessoas, por isso as oportunidades de formação inicial em EA ainda estão mais presentes em cursos relacionados às ciências da natureza como Biologia, Ecologia, Geografia, Agronomia e Engenharias Ambiental, Florestal etc. (SORRENTINO; FERRARO JÚNIOR, 2010; LOPES; ZANCUL 2012a). Portanto, no caso das professoras do ensino básico, que cursaram Licenciatura em Pedagogia, os cursos de extensão e/ou especialização acabam sendo as principais formas de inserção no campo da EA e não apenas uma opção de aperfeiçoamento (CARVALHO, 2002; MORALES, 2012). Muitas vezes, tais cursos são buscados para subsidiar um trabalho que já vem sendo desenvolvido em sala de aula.

Bem, na verdade eu já trabalho com o tema educação ambiental há anos. Então, antes de fazer a especialização que foi na UFSCar, que é o Coletivo Educador de São Carlos e região, eu já trabalhava com vários temas sem dar esse nome: educação ambiental [...] Eu não relacionava exatamente o que eu fazia, até por falta de conhecimento mesmo, de formação, como se tudo tivesse relacionado à educação ambiental. Surgiu o curso de especialização, eu fiz, foram dois anos e meio, desenvolvi um projeto na igreja São Nicolau e a partir daí eu acho que eu consegui dar uma formatada melhor nas ideias, ter uma percepção de educação ambiental diferente do que eu fazia (RAQUEL 8).

O município de São Carlos possui um importante histórico de atuação em EA e de formação de educadoras/es ambientais. Desde a década de 1980, a UFSCar, o Centro de Divulgação Científica e Cultural da USP - CDCC/USP e o Centro de Recursos Hídricos e Ecologia Aplicada da USP - CRHEA/USP oferecem cursos de extensão e aperfeiçoamento em EA, sendo que, em 1997, o CRHEA passou a oferecer o curso de Especialização em EA $e$ Recursos Hídricos. Em 2000, a Rede de Educação Ambiental de São Carlos - REA-SC e o Núcleo de Educação Ambiental do Alto Jacaré-Guaçu iniciaram uma série de eventos anuais de EA, dirigidos às/aos professoras/es e demais interessadas/os na temática. Em 2005, foi constituído o Coletivo Educador de São Carlos, Araraquara, Jaboticabal e região - CESCAR, cujo projeto Viabilizando a Utopia, financiado pelo Fundo Nacional de Meio Ambiente FNMA deu origem, entre outras ações, a um curso de especialização e extensão em EA entre 2007 e 2008. A UFSCar também oferece formação em educação ambiental para a comunidade em geral, via atividades de ensino e extensão (como as Atividades Curriculares de Integração Ensino, Pesquisa e Extensão) há mais de uma década. Além disso, desde 2001 a SME possui um apoio pedagógico para acompanhar e orientar as ações de EA nas escolas municipais. Assim sendo, acreditamos que todo esse movimento municipal em torno da EA (além das políticas públicas federais) tenha contribuído ao gerar uma demanda para a inserção dessa dimensão na rede municipal de ensino básico, sendo que as diversas oportunidades de as professoras participarem de algum tipo de formação já havia possibilitado um primeiro contato com a EA antes do ProMEA na Rede. De fato, das nove professoras entrevistadas, apenas duas se envolveram com a EA pela primeira vez no âmbito desse projeto. As outras sete já trabalhavam a dimensão ambiental anteriormente, sendo que duas delas fizeram o curso de especialização em EA oferecido pelo CESCAR. Logo, concordamos com Sorrentino e Ferraro Júnior (2010) que, para professoras/es do ensino básico, os projetos ambientais escolares consistem em uma importante porta de entrada no campo da EA, assim como cursos de formação oferecidos por universidades, ONGs, coletivos educadores etc.

Embora o caminho profissional tenha sido o meio de aproximação mais citado pelas professoras com o campo da EA, a busca de formação por meio dos cursos, ou mesmo a 
decisão de desenvolver um trabalho contemplando a dimensão ambiental em sala de aula são motivadas por diversos fatores, entre eles uma afinidade pessoal com a temática.

Eu acho muito importante estar aprendendo mais para preservar o planeta. A gente vê que hoje é muito importante ter esse cuidado. Está tendo tanta destruição, tanta coisa acontecendo, então é um tema que me chama atenção, eu gosto bastante de trabalhar com isso (CRISTINA 10).

Eu sempre uso aquela frase assim: quem ama cuida. Então, se eu gosto, eu faço isso por prazer, então eu quero que os meus alunos, sejam crianças ou adultos, que eu trabalho também com o EJA, que eles tenham amor, que eles gostem de fazer isso. Porque tudo o que você gosta, você tende a passar para a frente. A gente não guarda o que a gente gosta. O que eu gosto eu quero mostrar pros outros (LIDIANE 59).

As falas anteriores evidenciam motivações relacionadas tanto ao saber cognitivo quanto aos sentimentos, coincidindo com uma perspectiva freiriana, que pressupõe a indissociabilidade entre razão e emoção (FREIRE, 2010). Pesquisando as trajetórias de educadoras/es ambientais, Cassini (2010) também identificou que, embora a inserção efetiva na área tenha ocorrido, principalmente, por uma demanda profissional, a maioria já apresentava um contato e/ou uma preocupação prévia com a problemática socioambiental. No caso das professoras desta pesquisa, isso também se manifestou quando houve a necessidade de se inscrever em um dos cursos oferecidos pela SME na Semana de Formação dos Profissionais da Educação, em 2011. A opção de algumas delas foi pelo curso de EA devido a uma afinidade pessoal com o tema.

O curso que me chamou a atenção, né, que eu me detive, foi justamente a questão relacionada ao meio ambiente. O curso relacionado ao meio ambiente [...] Então eu me inscrevi no curso que já fazia parte do meu dia a dia mais pessoal assim, coisa minha e não relacionada ao trabalho, à escola (JULIA 8).

Algumas professoras citaram valores, atitudes e hábitos pessoais relacionados ao sujeito ecológico já na vida adulta, como motivação para trabalhar com a EA na escola.

Então durante vários anos do período que eu atuo nessa escola, eu tentei trazer pra eles um pouco da minha realidade pessoal porque na minha casa eu faço muitas coisas. Então, eu tenho a horta que é uma coisa que vem de família [...], tem a questão da coleta seletiva, da separação de resíduos, da economia mesmo, né? (JÚLIA 22).

A gente faz algumas experiências aqui em casa, de minhoca, de composteira. E aí esse assunto antigamente não fazia parte das minhas aulas, era de vez em quando, no dia da água, no dia do meio ambiente, que a gente falava. Mas aí como a gente começou aqui em casa, na nossa vida, mudar certos hábitos com a coleta seletiva, tudo, eu comecei a me interessar mais pelo tema, motivada pelo... [marido]. Aí, comecei a fazer na escola vários projetos (MÔNICA 11).

Essa afinidade pessoal, fruto de uma experiência extraescolar anterior ou externa ao exercício profissional, também pode ser considerada uma via importante de aproximação das professoras com a EA.

A fala da professora Mônica também exemplifica outro aspecto relevante identificado nas entrevistas: a influência mais direta de algumas pessoas na aproximação das professoras com a EA. No caso dessa professora, o marido foi seu maior incentivador e apoiador em todo o processo. Dias (2012) também verificou um papel de destaque para o outro na constituição das professoras enquanto educadoras ambientais. Para Freire (2010, p. 22), estamos "no mundo, com o mundo e com os outros", portanto, a experiência humana e, especialmente o aprendizado, acontecem na história e na relação com as outras pessoas.

As primeiras experiências profissionais com a EA, quando bem-sucedidas, foram citadas como uma motivação para continuar o trabalho em sala de aula e também para se envolver mais com o campo por meio de cursos de formação, participação em eventos etc. 
[...] procurando na revista Ciência Hoje das Crianças, ela [a diretora] viu um tal de eco teste que é um trabalho no rio que passa perto da escola. Então era um questionário que a gente aplicou e ela pediu super a minha ajuda, porque eu era bióloga, então tudo que era relacionado ao meio ambiente caía na minha mão [...] E foi um trabalho muito legal, muito legal mesmo [...] E eu empolgadíssima na época, falei: "nossa, eureka, achei meu caminho. É esse, quero seguir na educação ambiental" (FERNANDA 95).

O [marido] construiu uma composteira para mim [...] Fizemos lá na escola como experiência, que eu nunca tinha feito nada disso. Deu certo, apresentei até no EA de 2010 ou 2011[...] Eu apresentei, fiz um projeto e isso começou a me animar muito. [...] Então eu comecei a me animar de colocar esses temas no meio das minhas aulas [...], então todo ano eu faço um, dois, três, o que eu conseguir eu coloco nas minhas aulas (MÔNICA 19).

A professora Ana citou a questão financeira como um dos motivos que a incentivaram a começar a trabalhar com a EA: "E também [decidi assumir a função de EAL] porque ia entrar um dinheirinho a mais, eu tenho que ser sincera, e eu estava precisando muito na época e então foram esses os motivos no primeiro momento (ANA 18).

Embora, geralmente as propostas de EA sejam bem aceitas dentro das escolas, elas acabam se tornando responsabilidade da/o proponente, que as desenvolve no seu tempo livre, enfrentando a falta de tempo e/ou a sobrecarga de trabalho (CASSINI, 2010). Talvez, ainda hoje, as/os professoras/es tragam resquícios da identidade das/os professoras/es do século XIX: religiosas/os ou profissionais de outras áreas do conhecimento que exerciam a função docente de maneira secundária e voluntária (NÓVOA, 1999). Freire (1997) também faz uma crítica a essa identidade missionária da professora por meio da figura da tia, que reflete uma compreensão distorcida da tarefa da professora, resultando em uma desvalorização profissional. Assim, acreditamos que ao possibilitar que as professoras exercessem a função de EALs de forma remunerada, o ProMEA na Rede possibilitou um avanço importante do ponto de vista da institucionalização da EA na rede municipal de ensino, durante sua vigência (2011-2012).

É interessante notar que nenhuma professora citou diretamente, de maneira explícita, as vivências no meio ambiente durante a infância e/ou juventude como uma motivação para desenvolver atividades de EA na escola. Seriam essas vivências, devido a sua informalidade, consideradas um caminho menos válido de aproximação com a EA e por isso não foram citadas? No entanto, nós pudemos perceber que tais vivências foram citadas em outros momentos da entrevista, como no exemplo da professora Fernanda.

O meu pai tinha um sítio incrível, que tinha uma cachoeira no fundo que a gente brincava lá, quase todo o dia nas férias, sabe? [...] Eu sempre prestei atenção nas árvores, nos animais, sempre gostei muito [...] Eu gostava muito de animais, eu ajudava meu pai no sítio, dava vacina nos bois dele. Quando algum porco, acontecia alguma coisa, se machucava, eu que ia lá ajudar, curar as bicheiras, as coisas, tudo, eu adorava (FERNANDA 12).

O fato de as professoras não terem citado as vivências no meio ambiente como motivação para aproximação com a EA não quer dizer que elas não tenham sido significativas. As pesquisas com experiências de vida significativas têm gerado opiniões controversas entre os pesquisadores (GOUGH, 1999). Alguns defendem que tais investigações são capazes de identificar quais experiências podem produzir pessoas sensíveis e/ou comprometidas com a questão ambiental (PALMER, 1998; HSU, 2009), enquanto outros afirmam que as experiências relatadas não se constituem uma realidade absoluta, mas são (re)interpretadas como significativas, à luz do momento presente (CHAWLA, 1998), o que é coerente com a perspectiva na qual desenvolvemos esta pesquisa. Assim, acreditamos que as vivências no meio natural muito provavelmente trouxeram contribuições importantes para a 
formação da sensibilidade ambiental das professoras, porém não podemos assumir uma relação direta, tipo causa-efeito entre elas, o que seria subestimar a complexidade das experiências humanas ao longo da vida (PAYNE, 1999).

$\mathrm{Na}$ fala anterior, a professora Fernanda relata alguns aspectos interessantes relacionados a sua infância na chácara, como o brincar na natureza e o aprender a gostar e cuidar do meio ambiente. Iared e Oliveira (2013) também identificaram o lazer na natureza, especialmente as atividades espontâneas, como uma vivência importante na construção dos valores éticos e estéticos ambientais. Ainda, em se tratando da formação desses valores, a família tem aparecido como uma referência importante em vários outros estudos (PAYNE, 2005, 2010; DIAS, 2012; IARED; OLIVEIRA, 2013).

$\mathrm{Eu}$ acredito que educação ambiental, amor à natureza, a preservação do planeta, tudo isso que a gente faz, a gente não nasce com isso. Eu acho que a gente aprende [...] como é que você aprende a gostar? É vendo alguém trabalhar com muito carinho com isso, né, fazendo isso com muito carinho. Então você vê a pessoa fazendo isso com carinho, gostando daquilo, e você vai convivendo, você aprende a gostar também, né? Eu cresci com isso, então vendo as pessoas trabalharem com isso com muito carinho [...] Meu pai sempre trabalhou com terra. Meu pai sempre, ele pegava um punhadinho de terra e falava: "quem tem um pouquinho de terra não passa fome". Então, a questão do plantio: meu pai sempre plantou muito e eu cresci plantando (LIDIANE 7).

Em suas obras À sombra desta mangueira e Pedagogia da Esperança, Freire (2010, 1994) menciona diversas passagens da sua vida e a relação com sua família e amigos, refletindo sobre a importância dessas vivências na construção da sua identidade e da sua leitura de mundo atual. Porém, os valores transmitidos pela família não são aceitos passivamente pelos sujeitos, ao contrário, há uma negociação e uma (re)significação desses (PAYNE, 2010) por meio da reflexão sobre eles.

Eu sempre prestei atenção nas árvores, nos animais, sempre gostei muito, mas era uma outra relação, eu tinha uma outra relação com o meio ambiente. Era aquela coisa do meu pai agricultor, de tirar pro sustento mesmo, explorar, não tinha essa coisa da preservação (FERNANDA 12).

A partir do seu envolvimento atual com a EA, a professora Fernanda percebe que a relação com o meio ambiente que possuía na infância era uma relação mais utilitária, diferente da relação atual. É interessante notar que em nenhum momento da entrevista, a escola foi citada como referência na formação dos valores éticos e estéticos ambientais. Como já mencionado, segundo o referencial da hermenêutica filosófica, não significa que essa instituição não tenha trazido contribuições, porém a partir das vivências atuais, as professoras não atribuíram sentidos às experiências escolares. Grün (1994) acredita que, de fato, ao longo do tempo a escola tem valorizado apenas a dimensão cognitiva do processo de ensinoaprendizagem, desprezando sua dimensão axiológica. Nesse sentido, é importante que haja uma maior integração entre escola e família no sentido de trabalhar tais valores intencionalmente nos processos educativos.

\section{A construção da identidade das professoras como educadoras ambientais}

Quando questionadas diretamente se elas mesmas se consideravam educadoras ambientais, três professoras afirmaram que sim; outras três negaram categoricamente. Uma educadora se considerou em processo de se tornar educadora ambiental e as outras duas não souberam responder. Embora todas elas tivessem atuado como educadoras ambientais, percebemos que isso não garante uma identidade homogênea e nem definitiva como educadoras ambientais (CARVALHO, 2002), de maneira que a impossibilidade de atuação 
profissional pode se configurar como uma negação dessa identidade (LEME, 2008). Apesar da diversidade de respostas, pudemos evidenciar alguns aspectos que as professoras consideraram parte da identidade da/o educador/a ambiental. Assim, as professoras que atuaram como educadoras ambientais no contexto escolar estão em diferentes etapas da construção da identidade, que acontece por meio de múltiplos e variados caminhos, entre eles, o aprendizado por meio de cursos de EA.

$\mathrm{Eu}$ acho que eu tenho que estudar muito ainda. Gostei muito da experiência, mas eu acho ainda que tenho que correr muito atrás, ler muito, fazer mais cursos, porque assim eu ainda me acho uma curiosa no assunto, mas eu acho que tem muito ainda a estudar, a pesquisar ... (MÔNICA 166).

Para se identificarem como educadoras ambientais, algumas professoras sentem falta de uma formação em EA, especialmente no que se refere aos conceitos da área de biologia e ecologia. Acreditamos que tal preocupação reflete uma concepção naturalista da EA, pois reproduz o senso comum de que EA é coisa de biólogalo. Nesse sentido, elas acabam desvalorizando sua formação humana, que consideramos de grande relevância para a EA. Outras pesquisadoras (CARVALHO, 2002; CASSINI, 2010) perceberam que o autorreconhecimento das/os educadoras/es ambientais passa pela titulação formal, que colabora não apenas com os conhecimentos adquiridos, mas, também, com o reconhecimento pelos pares. Porém, por si só, estes não são suficientes para o autorreconhecimento das professoras como educadoras ambientais. Também é preciso atuar, ou seja, incorporar a dimensão ambiental nas práticas profissionais. Todas as professoras participantes desta pesquisa atuaram como educadoras ambientais no âmbito do ProMEA na Rede, durante pelo menos um ano letivo. Portanto, consideramos que a incorporação da dimensão ambiental na sua prática é parte da construção da sua identidade. A incorporação dos valores e hábitos do sujeito ecológico na vida pessoal também aparece como uma característica das professoras educadoras ambientais, corroborando os resultados obtidos por Cassini (2010) e Leme (2008).

Tem certos comportamentos, tem certas atitudes que eu adotei e eu tenho certeza que eu não vou voltar no que eu já fiz. Que eu já fiz muita coisa errada, com certeza, a gente faz, né? Já comprei várias embalagens de isopor e não parava para pensar, quando eu ia no supermercado, que o isopor não era uma coisa reciclável [...] hoje eu tenho essa preocupação de separar o que é reciclável, de dar um destino mais correto pro orgânico, de diminuir o consumo principalmente dos alimentos dentro da minha casa, de educar os meus filhos para o não desperdício... (RAQUEL 257).

Todas as ações de educação ambiental que aconteceram na escola [...] isso chegou até a minha casa [...] tem feito parte do dia a dia. Lógico que eu não sou perfeita. Tem hora que a gente falha também, mas eu tenho procurado colocar muitas coisas, que eu tenho aprendido com vocês e colocado em prática aqui na escola, na minha casa também... (LARA 113).

A formação da identidade profissional e pessoal estão muito relacionadas, de maneira que os processos de construção da identidade das professoras como educadoras ambientais acontecem concomitantemente à incorporação dos valores ecológicos nas suas vidas pessoais. Assim, a EA torna-se uma porta de entrada para o campo ambiental. Carvalho (2002) entende essa incorporação dos valores do sujeito ecológico na trajetória das/os educadoras/es ambientais como um tipo de militância, herdada do movimento contracultural. Nos arriscamos a afirmar que, no Brasil, essa militância de ideias e princípios constitui uma característica distintiva das/os educadoras/es ambientais e se manifesta em um compromisso pessoal com a busca de coerência entre o discurso e a prática de valores e atitudes ambientalistas.

Eu considero que eu trago contribuições em relação à questão de educação ambiental. Mas não que eu seja uma educadora ambiental. Talvez falte formação, falte a parte teórica ainda [...] Eu sinto que talvez pudesse ter feito mais, pudesse ter 
brigado mais, pudesse ter ido além. Não que eu não seja uma educadora ambiental, mas poderia ser melhor (JULIA 197).

$\mathrm{Na}$ fala da Julia, percebemos um certo grau de frustração pela pouca militância política, um sentido recorrente no campo ambiental, herdeiro dos movimentos ambientalistas (CARVALHO, 2002). Cassini (2010) identificou a presença do sentido da militância pelo envolvimento das/os educadoras/es ambientais em movimentos estudantis, órgãos de classe, entre outros, muitas vezes em diversos espaços ao mesmo tempo. A pouca militância identificada no caso das professoras se constitui em um fator de distanciamento da identidade do educador ambiental. Cabe questionar que outros sentidos poderiam ser atribuídos à militância no contexto atual? Outra característica bastante marcante das professoras que atuam como educadoras ambientais é a percepção de seu inacabamento (FREIRE, 2010). Independente de se autorreconhecerem como educadoras ambientais, muitas são as suas inseguranças e angústias, mostrando que elas se consideram educadoras ambientais inconclusas e, portanto, em processo de aprender mais.
$\mathrm{Ai}$, eu acho que eu tenho bastante ainda que aprender, pois tenho um pouco de insegurança. Assim, tem algumas ações que eu ainda fico em dúvida (Cristina 70). Em parte eu sou uma educadora, porque eu vivo isso, eu vivo isso. E não é só dentro da escola. Eu vivo na rua [...] Então nesse sentido, eu acho que então eu sou uma educadora ambiental, mas quando eu penso que eu não dou muito conta, eu falo: será que eu sou? (LIDIANE 191).

Esse sentimento de discordância entre as características do sujeito e do grupo é entendido como uma crise de identidade (DILLON; KELSEY; ARISTIZABAL, 1999). Algumas professoras não reconhecem a sua identidade como sendo aquela da educadora ambiental, pois consideram que não cumprem com os requisitos necessários para isso, em termos de discurso, valores e hábitos relacionados ao sujeito ecológico. Em alguns relatos também aparece certa frustração por não conseguir envolver as/os demais professoras/es da escola, bem como os familiares nos processos educativos.

Eu percebo que o que falta assim para eu poder talvez me realizar um pouco mais como profissional é engajar mais os colegas de trabalho... (Raquel 201).

O meu pai sempre queimou lixo, até hoje ele queima lixo. Eu não consegui ainda fazer ele parar de fazer isso, ele adora veneno, ele fala que se não por um veneninho lá o pêssego não produz, o não sei o que não produz... (FERNANDA 57).

Apesar da família ter um papel bastante relevante na formação dos valores éticos e estéticos com relação ao meio ambiente, como já dito anteriormente, as novas gerações (re)significam e (re)constroem os valores transmitidos pelas gerações anteriores a partir da reflexão e da interpretação das suas experiências (DILLON; KELSEY; ARISTIZABAL, 1999; PAYNE, 2010). O sujeito não abandona seu próprio horizonte para se entregar ao horizonte do outro. Pelo contrário, ele amplia seu horizonte para que possa integrar o outro, produzindo uma nova identidade (GADAMER, 2005).

Ainda, em se tratando do inacabamento, as professoras falaram das suas incoerências pessoais. Embora elas reconheçam algumas mudanças no que se refere à incorporação dos valores e atitudes do sujeito ecológico em sua vida pessoal, muitas são as atitudes que elas identificam como incoerentes e/ou contraditórias.

Eu tenho um certo cuidado, mas eu não vou deixar de comprar um produto numa hora de necessidade porque ele está numa bandeja de isopor se eu não tenho um outro equivalente... Ali, tô precisando daquilo naquele lugar, eu não vou pegar meu carro, sair dali... "Ah não, não vou comprar porque está na bandejinha, vou ficar sem”. Essa consciência ainda não tenho (JULIA 211).

Que nem a Fernanda, ela já tá tomando uma postura diferente na vida dela, ela pensa até para ir comer na pizzaria, porque ela acha que aquela borda que a gente tá 
jogando fora, ficou muito forte isso pra mim, é água que tá sendo desperdiçada. E é verdade! Só que eu acho que ainda, eu não deixaria jamais de comer pizza na pizzaria por conta da borda (ANA 266).

Se tomarmos o sujeito ecológico como um modelo utópico, a identidade ecológica plena nunca seria atingida. As incoerências e o inacabamento humano presentes em cada um/a de nós também estão presentes nas/os educadoras/es ambientais. No entanto, esse processo de aproximação com a EA proporciona, a partir do diálogo com os pares, uma reflexão sobre as práticas cotidianas, o que se reflete na busca dessa coerência. Não é possível separar a formação profissional da pessoal, portanto, assim como os cursos, a formação acadêmica e as experiências profissionais, as experiências de vida e as relações sociais também possuem um papel fundamental na formação da/o identidade da/o educador/a ambiental (FREIRE, 2005).

\section{Considerações finais}

A hermenêutica filosófica e a pedagogia dialógica podem contribuir no estudo de como as identidades ambientalistas educativas são construídas e sustentadas ou transformadas a partir da reflexão sobre as experiências vividas e do diálogo com o outro. No caso de professoras do ensino básico, que atuaram como educadoras ambientais, a aproximação com a EA tem acontecido por diferentes vias que se inter-relacionam de maneira complexa. As oportunidades de realizar cursos ou desenvolver atividades de EA em sala de aula são motivadas por afinidades pessoais com a temática, o que revela o importante papel das vivências pessoais e das relações intersubjetivas nesse processo. Os projetos de EA nas escolas constituem uma importante forma de aproximação com a EA, pois as oportunidades que as professoras têm de inserir a dimensão ambiental em suas práticas estão bastante relacionadas à busca de respaldo teórico-metodológico por meio de cursos de formação, contribuindo para a construção das suas identidades como educadoras ambientais. Portanto, a partir da atuação em EA, as professoras constroem uma identidade ecológica, ainda que heterogênea e provisória, sujeita à oportunidade de atuação, passando a se identificar com o ideário ambiental não apenas no contexto profissional, mas também pessoal. No contexto escolar, a EA torna-se, então, uma via de acesso ao campo ambiental, de maneira que a institucionalização da EA no ensino básico é essencial para permitir a continuidade da construção dessa identidade por parte das/os professoras/es e, consequentemente, também das ações educativas socioambientais.

\section{Referências}

BARDIN, L. Análise de Conteúdo. 4 ed. Lisboa: Edições 70, 2008.

BRASIL. Lei 9.795, de 27 de abril de 1999. Dispõe sobre a educação ambiental, institui a Política Nacional de Educação Ambiental e dá outras providências. Brasília: Casa Civil. Disponível em: <http://www.planalto.gov.br/ccivil_03/leis/L9795.htm>. Acesso em: 8 dez. 2016.

BRASIL. Ministério do Meio Ambiente. Programa Nacional de Educação Ambiental. ProNEA Brasília: MMA, 2005.

BRASIL. Resolução CNE $n^{o}$ 2, de 15 de junho de 2012. Diretrizes Curriculares Nacionais em Educação Ambiental. Brasília: Conselho Nacional de Educação, 2012.

CARVALHO, I. C. M. A invenção ecológica: narrativas e trajetórias da educação ambiental no Brasil. 2.ed. Porto Alegre: Editora da UFRGS, 2002. 
CARVALHO, I. C. M. Biografia, Identidade e Narrativa: elementos para uma análise hermenêutica. Horizontes Antropológicos, Porto Alegre, ano 9, n.19, p.283-302, Jul. 2003.

CARVALHO, I. C. M. Invenção e autoinvenção na construção psicossocial da identidade: a experiência constitutiva do/a educador/a ambiental. In: GUIMARÃES, M. (Org). Caminhos da educação ambiental. Campinas: Papirus, 2006. p.31-50.

CARVALHO, I. C. M.; GRÜN, M.; AVANZI, M. R. Paisagens da compreensão: contribuições da hermenêutica e da fenomenologia para uma epistemologia da educação ambiental. Cadernos CEDES, Campinas, v. 29, n. 77, p. 99-116, jan/abr, 2009.

CASSINI, L. F. Trajetória de Educadores Ambientais: revelando os caminhos trilhados. 2010. 213f. Dissertação (Mestrado em Educação para a Ciência) - Faculdade de Ciências, Universidade Estadual Paulista, Bauru, 2010.

CHAWLA, L. Research methods to investigate significant life experiencies: review and recomendations. Environmental Education Research, s/l, v.4, n.4, p.383-397, 1998.

DIAS, C. M. S. Possibilidades e limites no uso da abordagem (auto) biográfica no campo da educação ambiental? In: GALIAZZI, M. C.; FREITAS, J. V. (Orgs.). Metodologias Emergentes de Pesquisa em Educação Ambiental. 2. ed. Ijuí: Unijuí, 2007. p.151-178.

DIAS, V. de M. T. Constituindo-se educador ambiental: um estudo das narrativas dos professores que fazem educação ambiental na escola. 2012. 121f. Dissertação (Mestrado em Educação em Ciências) Programa de Pós-graduação em Ciências: química da vida e saúde, Universidade Federal do Rio Grande, Rio Grande, 2012.

DILLON, J.; KELSEY, E.; ARISTIZABAL, A. M. D. Identity and Culture: theorizing emergent environmentalism. Environmental Education Research, s/1, v.5, n.4, p. 353-363, Nov. 1999.

DUBAR, C. A crise das identidades: a interpretação de uma mutação. Porto: Edições Afrontamento, 2006.

FREIRE, P. Pedagogia do Oprimido. 8.ed. Rio de Janeiro: Paz e Terra, 1980.

FREIRE, P. Pedagogia da esperança: um reencontro com a pedagogia do oprimido. 3. ed. Rio de Janeiro: Paz e Terra, 1994.

FREIRE, P. Professora sim, tia não: cartas a quem ousa ensinar. São Paulo: Olho d'Água, 1997.

FREIRE, P. Pedagogia da Indignação: cartas pedagógicas e outros escritos. São Paulo: Editora UNESP, 2000.

FREIRE, P. A Educação na Cidade. 6. ed. São Paulo, Cortez, 2005.

FREIRE, P. À sombra desta mangueira. 9. ed. São Paulo: Olho D’Água, 2010.

GADAMER, H. - G. Verdade e Método. Tradução de Flávio Paulo Meurer. 7.ed. Petrópolis: Vozes / Bragança Paulista: Editora Universitária São Francisco, 2005 (Vol. 1).

GOUGH, S. Significant life experiences (SLE) research: a view from somewhere. Environmental Education Research, s/l, v.5, n.4, p. 353-363, 1999. 
GRÜN, M. Uma discussão sobre valores éticos em educação ambiental. Educação \& Realidade, Porto Alegre, v. 19, n. 2, p. 171-195, 1994.

GUIMARÃES, J. de M. M.; ALVES, J. M. Formação de professores na área de Educação Ambiental: uma análise dos anais da ANPEd (2009-2011). Pesquisa em Educação Ambiental, Rio Claro, v. 7, n. 1, p. 49-67, jun, 2012.

HALL, S. Quem precisa de identidade? In: SILVA, T.T. (Org.) Identidade e Diferença: perspectivas dos estudos culturais. Petrópolis: Vozes, 2000. p. 103-131.

HART, P. Narrative, Knowing, and Emerging Methodologies in Environmental Education Research: Issues of Quality. Canadian Journal of Environmental Education, Ontário, Canadá, v.7, n.2, p. 140165, Spring. 2002.

HERMANN, N. Hermenêutica e Educação. Rio de Janeiro: DP\&A, 2002.

HSU, S-J. Significant life experiences affect environmental action: a confirmation study in eastern Taiwan. Environmental Education Research, s/1, v.15, n.4, p. 497-517, 2009.

IARED, V. G.; DI TULLIO, A.; OLIVEIRA, H. T. de. Uma aproximação entre Gadamer e Paulo Freire como contribuição para refletir sobre a pesquisa em Educação Ambiental. In REUNIÃO ANUAL DA ASSOCIAÇÃ̃O DE PÓS-GRADUAÇÃ̃O E PESQUISA EM EDUCAÇÃO, 35, 2012, Porto de Galinhas. Anais... ANPED, 2012. Disponível em: <http://35reuniao.anped.org.br/images/stories/trabalhos/GT22\%20Trabalhos/GT22-1395_int.pdf >. Acesso em: dez. 2016.

IARED, V. G.; OLIVEIRA, H. T. de. Formação de valores estéticos e éticos e o Cerrado. In ENCONTRO DE PESQUISA EM EDUCAÇÃO AMBIENTAL: Problematizando a Temática Ambiental na Sociedade Contemporânea,7, 2013, Rio Claro. Anais... Rio Claro: UNESP, 2013. Disponível em: <http://www.epea.tmp.br/epea2013_anais/pdfs/plenary/0104-1.pdf >. Acesso em: dez. 2016.

LAWN, C. Compreender Gadamer. 2.ed. Petrópolis: Vozes, 2010.

LEME, P. C. S. Formação e Atuação de Educadores Ambientais: análise de um processo educativo na universidade. Tese (Doutorado em Educação) - Programa de Pós-Graduação em Educação, Universidade Federal de São Carlos, São Carlos, 2008.

LOPES, T. M.; ZANCUL, M. C. de S. A temática ambiental no curso de Pedagogia de uma universidade pública paulista. Pesquisa em Educação Ambiental, Rio Claro, v.7, n. 1, p. 154-166, Jun. 2012.

LOPES, T. M.; ZANCUL, M. C. de S. A inclusão de temas ambientais nos cursos de ciências biológicas de universidades públicas paulistas. Revista Eletrônica do Mestrado em Educação Ambiental, Rio Grande, RS, v.29, Jul/Dez. 2012a.

LUDKE, M.; ANDRÉ, M. E. D.A. Pesquisa em educação: abordagens qualitativas. São Paulo: EPU, 1986.

MINAYO, M. C. de S. O desafio do conhecimento: pesquisa qualitativa em saúde. 12. ed. São Paulo: Hucitec, 2010.

MORAES, R.; GALIAZZI, M. do C. Análise Textual Discursiva. 2.ed. Ijuí: Unijuí, 2011. 
MORALES, A. G. A formação do profissional educador ambiental: reflexões, possibilidades e constatações. 2.ed. Ponta Grossa: Ed. UEPG, 2012.

NÓVOA, A. O passado e o presente dos professores. In: . (Org.). Profissão Professor. 2.ed. Porto: Porto Editora, 1999. p.13-34.

OLIVEIRA, H. T. de.; FARIAS, C. R. de O.; PAVESI, A. Educação Ambiental no ensino superior brasileiro: caminhos percorridos e perspectivas para políticas públicas. Revista Brasileira de Educação Ambiental, Brasília, v.3, n.1, p.91-101, Jun. 2008.

PALMER, J. A. et al. An Overview of Significant Influences and Formative Experiences on the Development of Adults' Environmental Awareness in Nine Countries. Environmental Education Research, s/l, v.4, n.4, p. 445-464, 1998.

PAYNE, P. The Significance of Experience in SLE Research. Environmental Education Research, s/l, v.5, n.4, p. 353-363, 1999.

PAYNE, P. Identity and Environmental Education. Environmental Education Research, s/l, v.7, n.1, 2000.

PAYNE, P. Families, Homes and Environmental Education. Australian Journal of Environmental Education, s/l, v. 21, p.81-95, Jan. 2005.

PAYNE, P. Moral spaces, the struggle for an intergenerational environmental ethics and the social ecology of families: an "other" form of environmental education. Environmental Education Research, s/l, v.16, n.2, p.209-231, 2010.

SÃO CARLOS. Conselho Municipal de Defesa do Meio Ambiente - COMDEMA. Resolução 001, de 26 de junho de 2008. Estabelece o Programa Municipal de Educação Ambiental - ProMEA. São Carlos: CONDEMA, 2008.

SÃO CARLOS. Município. Lei 14.795, de 28 de novembro de 2008. Dispõe sobre a política Municipal de Educação Ambiental. São Carlos: Câmara Municipal de São Carlos, 2008a.

SORRENTINO, M.; FERRARO JÚNIOR, L. A. Aprendendo nos caminhos da educação ambiental: uma construção de bifurcações heurísticas. In: DIB-FERREIRA, D.-R.; GUERREIRO, J. (Orgs.). $O$ VI Fórum Brasileiro de Educação Ambiental: participação, cidadania e educação ambiental. Niterói: Instituto Baía de Guanabara, 2010. p.48-62.

SPADARO, P. F. et al. Identity and externalities toward sustainability. In: RAHMAN, H.; RAMOS, I. (Orgs.) Cases on SMEs and Open Innovation: applications and investigations. Hershey, EUA: IGI Global, 2012. p.100-125.

TESTA, E. Hermenêutica Filosófica e História. Passo Fundo: UPF, 2004. 